\title{
Study Monitoring Visit
}

National Cancer Institute

\section{Source}

National Cancer Institute. Study Monitoring Visit. NCI Thesaurus. Code C142709.

A visit to a study site to review the progress of a clinical study and to ensure protocol adherence, accuracy of data, safety of subjects, and compliance with regulatory requirements and good clinical practice guidelines. (ICH) 